\title{
Mulheres e Literatura: Sob a perspectiva do sublime
}

\author{
Rosana Cássia Kamita \\ Universidade Federal de Santa Catarina / CNPq
}

Resumo: A literatura pode ser percebida a partir de determinados paradigmas considerados referenciais e $a$ priori. No entanto, o sentimento sublime permite reconhecer o excesso e a ausência de regras préestabelecidas, instaurando um espaço diferenciado para a percepção da literatura em suas várias dimensões, tanto no que se refere à produção e recepção de textos literários, quanto em relação às abordagens teóricocríticas empreendidas. A proposta deste texto é a de refletir sobre a literatura de autoria feminina como espaço plural e transitório, de resistência a padrões instituídos, aproximando-a do sublime, o qual se apresenta como possibilidade de constantes deslocamentos, admitindo o ilimitado, o informe e o paradoxal. 0 sublime trabalha no nível da tensão e da instabilidade e visto sob o prisma literário é a expectativa do que está por vir, ultrapassando os limites do belo instituído. As categorias do belo e do sublime se distinguem na relação possível com o objeto, o primeiro possuindo a capacidade de apresentá-lo, enquanto o último o concebe sem uma regra que o especifique. A literatura de autoria feminina (como outras manifestações diferenciadas que se distingam de padrões) se estabelece como fissura/fratura de uma pretensa hegemonia literária.

Palavras-chave: literatura, sublime, escritoras

\footnotetext{
Abstract: Literature can be approached from certain referential and a priori paradigms. However, the sublime allows us to recognize the excess and the lack of pre-established rules, introducing a differentiated space for the perception of literature in its various dimensions, both in terms of the production and reception of literary texts, and in relation to the Theoretical and critical approaches undertaken. The purpose of this text is to reflect on women's writing as a plural and transitory space of resistance to established standards, approaching the sublime, which presents itself as a possibility of constant displacement, assuming the 
unlimited, the formless and the paradoxical. The sublime works at the level of tension and instability and, from a literary point of view, it is the expectation of things to come, exceeding the limits of the beautiful. The categories of the beautiful and the sublime can be distinguished by the relation established with the object, the first having the ability to present it, while the latter can only conceive it, without the ability to specify it. The women's literature (as any other event which doesn't follow standard rules) establishes itself as a fissure / fracture regarding a supposed literary hegemony.

Keywords: literature, sublime, women writers

A reflexão crítica proposta por Kant perpassa três enfoques divididos entre a Crítica da Razão Pura (1781), Crítica da Razão Prática (1788) e Crítica da Faculdade de Julgar (1790), considerando que, em relação a esta última, a reflexão estética aparece em destaque, especialmente em "Analítica do Sublime". Como aponta Lyotard em Lições Sobre a Analítica do Sublime (1993), psicologicamente falando, o prazer e o desprazer são os responsáveis por pautar a faculdade de julgar, centrando-se, todavia, não no objeto, mas no sujeito, estabelecendo uma relação de tautegoria, na qual o sujeito informa o "espírito" sobre o seu "estado", como um raio, provocando um curto circuito do próprio pensamento.

Na terceira crítica, o sentimento de prazer e de desprazer é considerado como uma "faculdade da alma" e esse sentimento não aparece necessariamente associado a uma representação, mas à sensação [aisthèsis]. Na análise sobre o pensamento kantiano, a reflexão pura se refere à capacidade do pensamento de perceber que não há critérios precedentes para o atual estado em que se encontra. O sublime, por ser uma categoria relacionada à reflexão pura, seria diferenciado do belo, categoria pré-determinada por modelos. 0 sublime proporciona novas possibilidades no contato com a arte, já que não existe um a priori, uma vez que representa sem que haja um conceito determinado referente a um objeto.

Segundo Kant, o sentimento sublime não é provocado pelas formas da natureza, mas por sua grandeza, magnitude que se expõe sem que o espírito seja capaz de apreendê-la. 0 pensamento crítico tenta julgar essa grandeza no jogo das faculdades, em busca por sua 
compreensão. A proposta de Lyotard (1993) é considerar o sublime ao longo do tempo e nessa trajetória concluir que essa questão permaneceria com grande impacto no presente, ou seja, a proposta é refletir sobre o sublime nas artes em uma mirada contemporânea, reconhecendo suas reverberações na atualidade.

O belo e o sublime possuem pontos em comum, como o fato de agradarem por si mesmos e serem universalmente válidos, no entanto, como alerta Lyotard (1993), as discrepâncias não tardam a surgir. 0 juízo sobre o belo se estabelece a partir da forma apresentada pelo objeto, a qual, por sua vez, assume uma limitação em relação ao belo. 0 sublime, ao contrário, transita entre o ilimitado e o sem-forma, portanto, uma das diferenças entre belo e sublime reside nesse caráter ditado pelo limite do objeto. Diferentemente do belo, o sentimento sublime pauta-se pela emoção, emoção essa fundamentalmente contraditória. 0 pensamento kantiano aponta que a natureza contribui para despertar o sentimento sublime, não por suas formas, mas por sua grandeza e força. Aproximando essa conceituação à literatura, teríamos que a perspectiva não está centrada na mudança em si, a qual, uma vez que ocorresse, estabeleceria uma definição da arte - no sentido etimológico do fim - porém, na possibilidade de mudança, o que ilumina a reflexão sobre o sublime através de diferentes épocas e estilos, pois sempre haverá uma nova possibilidade para as manifestações literárias e o sublime é esse estado de expectativa pelo devir. O sublime trabalha no nível da tensão e da instabilidade, e visto sob o prisma literário é a expectativa do que está por vir, o sentimento de ultrapassar os limites do belo. As categorias do belo e do sublime se distinguem na relação possível de ser estabelecida pelo objeto, o primeiro possuindo a capacidade de apresentá-lo, enquanto o último o concebe sem uma regra que o especifique.

Assim, através do sentimento sublime a arte é sempre impulsionada a repensar seus limites. Conforme Lyotard (1993) assinala a partir de Kant, o sublime traz em si a melancolia, a dor de uma falta, a nostalgia da forma que remete à limitação. 0 conceito do sublime não é apresentável, pois mostra justamente a incapacidade de apresentação através de formas. As estéticas do belo e do sublime se tangenciam nessa tensão, uma delas 
voltada às regras e que se mantém em mínimos desafios; a outra, "absoluta ou minimal”, desafiando os conceitos.

O juízo estético do belo pressupõe a forma de um objeto, o qual será avaliado a partir de juízos particulares, porém, com a pretensão de universalidade, uma vez que tal julgamento se fundamentará em modelos e paradigmas instituídos. 0 juízo estético do sublime, ao contrário, dirige-se aos objetos informes, ilimitados, em uma quase impossibilidade de representação. Em um dado sistema, o belo está submetido a regras e leis, o sublime radica em um princípio de liberdade.

A teoria do juízo estético de Kant se mostrou como um enfoque pertinente para se ponderar sobre a arte contemporânea, sua efemeridade e limites entre o apresentável e o inapresentável. Porém, é importante ressaltar, o sublime não está restrito a nenhum período específico, trata-se de um conceito que permite refletir sobre os limites da arte. 0 sublime enseja a possibilidade de repensar as categorias de análise e de crítica que são utilizadas a partir de novas possibilidades que se apresentam como informes, ou exemplos a priori, e que exigem alterações de princípios e padrões pré-estabelecidos. 0 paradigma do belo é confrontado pela inquietação do sublime. 0 belo estabelece as condições de apresentação e recepção da arte, mas não se detém sobre o inesperado, sobre as experimentações. 0 juízo estético sublime expõe a crise, a fratura, em um momento de ruptura com o compreensível, apresenta-se com a marca do excessivo, do absoluto, do infinito. Uma vez que determinadas obras se afastem dos padrões estabelecidos, surge a oportunidade de se repensarem as possibilidades críticas e estéticas da literatura.

No livro A Filosofia Crítica de Kant, Deleuze ressalta que o sentimento sublime é experimentado de forma diferente do sentimento do belo, pois ocorre diante de uma manifestação disforme, perante a qual os limites são confrontados (Deleuze 2000). E assim, ante o imenso, no sentido da capacidade possível de apreensão, a imaginação não encontra pressupostos. A impotência em face do desconhecido permite repensar o estabelecido, uma vez que reconhece a existência de outras possibilidades, ainda que em determinado momento não existam condições estabelecidas para a sua apreensão e compreensão. Através do sentimento sublime a imaginação se encontra livre de suas balizas. 
Logo, o que aqui se pretende é partir do pressuposto de que o pensamento sublime possa ser considerado como oportunidade de reavaliar o já estabelecido e a perspectiva de se conceber a literatura a partir de novas abordagens, tanto de sua manifestação quanto de sua crítica e recepção. As convenções literárias são desafiadas pelo sentimento sublime, extrapolando os limites do belo, e o que o sublime feminista propõe é um posicionamento estético e ético, no sentido de não se perceber "o outro" como ameaça, mas a partir do reconhecimento da dimensão dinâmica e plural que a literatura possui. Esse espaço de legitimação ao "diferente" não se constitui em antítese, mas coexistência de possibilidades diversas, sem necessariamente uma hierarquização, constituindo-se como resistência à homogeneização coercitiva.

A Crítica da Faculdade de Julgar ensejou estudos realizados por Jacques Derrida, destacando-se a obra La Verité en Peinture, publicada em Paris, em 1978, e ainda sem tradução no Brasil. Neste livro, em especial no capítulo intitulado "Párergon", o autor se questiona sobre o objeto da terceira Crítica e constrói uma argumentação sobre o sublime considerando os conceitos do párergon e do colossal, os quais aparecem de maneira breve, porém significativa, em Kant.

Derrida retoma a distinção entre o juízo reflexivo e o juízo determinante, à qual remete em direção ao belo e ao sublime. Quando a faculdade de julgar - em sua dimensão ampla, constituída por regras, leis - parte do pensamento geral, ela determina o particular; já a operação inversa não oferece ao juízo reflexivo um princípio basilar e o exemplo ocorre antes da lei que o pudesse determinar. Assim, o juízo determinante trabalha a partir de exemplos capazes de oferecer as bases para o contato com o objeto e o juízo reflexivo parte do exemplo cujo conceito nos falta.

Em uma representação de um objeto consideramos seu cerne, seu interior, o ponto central ao qual se dirige a atenção. Porém, é possível examinar o que subsidiariamente acompanha o objeto, aquilo que não se constitui em parte integrante, mas realça a apresentação de tal objeto, e esse elemento extrínseco é o párergon. Ele não lhe pertence necessariamente, mas o acompanha e, em certa medida, pode complementá-lo. Derrida cita como exemplos as molduras dos quadros, as vestes das estátuas ou as colunas de 
edificações, as quais atuam como aditivos do objeto principal. No entanto, para serem considerados párerga, não basta julgá-los em sua exterioridade ou como excedentes, mas reconhecer neles o laço estrutural que se estabelece entre o ergon (a obra) e o párergon, o qual remete a uma falta que se situaria no interior da própria obra. 0 autor destaca que o párergon representa a falta presente no ergon, mas a qual não é possível determinar, situar ou delimitar, o párergon admite, portanto, uma falta interna. Derrida atesta que os párerga não apenas separam o interior, como aponta Kant, mas são limítrofes também em relação ao exterior, ou seja, à parede onde o quadro é fixado, por exemplo. 0 párergon estaria situado, portanto, entre a obra e seu campo de inscrição histórico, político e social.

Em uma breve citação na terceira crítica, Kant refere-se ao colossal: "Colossal (...) é denominada a simples apresentação de um conceito, o qual é para toda exposição quase grande demais" (Kant 2002: 99). O autor prossegue, afirmando que a apresentação de determinado conceito apresenta dificuldades "pelo fato de que a intuição do objeto é quase grande demais para a nossa faculdade de apreensão" e termina sua argumentação reiterando que o sublime não se apresenta determinado por nenhum fim. Derrida trabalha então com a ideia do colossal e detém-se sobre sua magnitude. Uma coluna, de medida moderada, com tamanho mensurável, não corresponde ao que se crê colossal. Em sua busca para exemplos de sublime, Kant não os encontra nas produções artísticas, pois considera que as mesmas recebam formas e dimensões reconhecidas e determinadas. 0 artista apresenta sua obra moldando-a, definindo-a, mas o sublime ultrapassa as medidas, proporcionalidades e determinações. Assim, o sublime não é apenas muito elevado, ele é absolutamente elevado, e não é possível compará-lo a pressupostos. Logo, uma coluna artisticamente erigida não atinge o atributo absoluto do sublime. Mas a indagação que Derrida se faz é: e o colossal? As obras de arte finitas e conformadas são colocadas a par do imenso, do excessivo, do exemplo a priori, cujo conceito é quase grande demais para uma apresentação. O colossal é o quase-demais, apresentado como um conceito, sem necessariamente uma aproximação empírica, o sujeito estaria diante de uma apresentação quase grande demais para ser apreendida e compreendida. 0 colossal, portanto, não é o inapresentável, mas o quase inapresentável. 
Não haverá sublime na arte se ela estiver de acordo com a natureza, submetida às condições previamente convencionadas e conhecidas. Se a arte dá forma e pode limitar através do párergon, não haverá párergon para o sublime. 0 párergon é excluído pela ideia do colossal, pois este é determinado justamente a partir de sua indeterminação, conforme o destaca Derrida. Retoma-se, então, a consideração do belo como definível em seu contorno e do sublime como indefinível, tanto em sua forma quanto em sua compreensão. 0 sublime somente existirá pelo excesso, pelo quase grande demais, considerando as perspectivas do infinito e do absoluto. Derrida destaca que a negatividade do sublime não se distingue apenas da pretensa positividade do belo, mas se dirige à capacidade de julgar. Na transposição do sublime para a arte, o colossal representa a manifestação passível de ser percebida como quase grande demais e que exigirá, ao se assumir como exemplo a priori, a construção de regras, princípios ou leis que possam tornar a ideia compreensível. 0 colossal é o vislumbre de possibilidade de representação do inapresentável, do infinito. 0 sublime comporta a incomensurabilidade violenta do impacto e que não reside no objeto, mas no sujeito, segundo Derrida, sentimento provocado pela inadequação de várias faculdades e potências.

O sublime enseja a possibilidade de repensar as categorias de análise e de crítica que são utilizadas a partir de novas possibilidades que se apresentam como informes, ou exemplos a priori, e que exigem alterações de princípios e padrões pré-estabelecidos. 0 paradigma do belo é confrontado pela inquietação do sublime, o belo estabelece as condições de apresentação e recepção da arte, mas não se detém sobre o inesperado, sobre as experimentações. 0 sublime se situa nesse espaço, entre o prazer da descoberta de algo novo e o desprazer de não conseguir apreendê-lo ou compreendê-lo, reconhecimento de uma arte dinâmica, que subverte constantemente as regras que se lhe deseje imputar. Como anteriormente exposto, a faculdade de apresentação falha diante de uma ideia desconhecida, o que impulsiona o pensamento a situar-se fora dos padrões estabelecidos. Esse impacto inicial apresenta um limite com o qual a imaginação se depara, justamente nessa impossibilidade de representação. 0 pensamento desafia seu próprio limite pela desmedida do que se apresenta, porém, como aponta Lyotard (1993), ainda que tal 
aconteça, ocorre de forma insuficiente. 0 juízo estético sublime expõe a crise, a fratura, em um momento de ruptura com o compreensível, apresenta-se com a marca do excessivo, do absoluto, do infinito.

Conforme destaca Pedro Süssekind em "Schiller e a atualidade do sublime", os últimos anos trazem vários textos nos quais se reflete sobre o sublime, intensificando o debate ao mesmo tempo em que se demonstra o interesse suscitado pelo tema. Dentre essas publicações, o autor destaca Du Sublime reunindo textos de Lyotard, Jean-Luc Nancy, Derrida, Deleuze, entre outros (Deguy/Nancy 1988). Para exemplificar a atualidade do tema, Süssekind cita uma expressão encontrada no texto de Nancy "L'Offrande Sublime" de que "o sublime está na moda" (Süssekind in Schiller 2011: 76). Nesse texto, segue-se, após essa afirmação, o questionamento sobre o que tem a oferecer o conceito atual do sublime ao que o autor responde ser a oferta mesma o que há a ser oferecido. Segundo Nancy, considerar o sublime equivale a considerar a finitude da arte em todos os seus sentidos de expressão, pois uma vez concebida como representação e tida como finalizada, torna-se uma arte morta. Para o autor, o que aparece em pauta nas artes não é a representação da verdade, mas a representação da liberdade.

Como aponta Nancy, essa espécie de "renascimento" do conceito de sublime traz em si a noção de deslocamento em direção à teoria moderna, deslocamento este que compreende a dimensão do sublime contemplando as manifestações artísticas (e literárias, mais especificamente), retomando um elo considerado por Longino em seu tratado e ao qual Kant não necessariamente associa. Esse pensamento diacrônico em relação ao sublime reverbera sincronicamente, mantendo-o como princípio teórico válido para subsidiar o estudo da literatura atual.

Em Um teto todo seu Virginia Woolf (1985) discorre sobre as mulheres e a ficção, entrecruzando os gêneros ensaístico e literário, registrando um posicionamento que vem há anos sendo motivo de reflexões e debates. A partir de uma personagem criada por ela, as apreensões, receios e limitações femininas foram abordados para que possamos compreender melhor os motivos que explicam a participação das mulheres na literatura. Logo no início da narrativa, a primeira transgressão: uma mulher deixou-se absorver de tal 
forma por seus pensamentos que se afastou da trilha a ela permitida e invadiu território proibido, o caminho de uma universidade que estaria aberto apenas a quem pertencesse àquele mundo. Um bedel de olhar severo mostrou-lhe a impertinência de sua atitude, o que a fez recuar para o percurso de cascalhos a ela destinado. Outro local "sagrado" era a biblioteca, à qual ela não pôde adentrar, pois não possuía condições para isso: “(...) as damas só são admitidas na biblioteca acompanhadas por um Fellow da Faculdade ou providas de uma carta de apresentação" (Woolf 1985: 13). No entanto, haveria um aspecto importante a ser considerado: não pagava tributo às convenções das quais esse espaço literário era guardião, assim sendo, ao analisar essa questão, pensou "em como talvez seja pior ser trancada do lado de dentro (...)" (idem: 33).

Virginia Woolf abordou de forma realista, que a única maneira de conquistar espaço no mundo das letras seria as mulheres garantirem "quinhentas libras por ano e um quarto com fechadura na porta (...)" (idem: 137). Seus argumentos circunscrevem aspectos amplamente debatidos, baseados na extrema vinculação feminina ao papel de mãe e esposa, o que pressupunha que não houvesse necessidade de estudar, pois se imaginava que para cumprir esses papéis as mulheres possuíssem dons que faziam parte de sua natureza.

A participação feminina no campo literário ou não se efetivava ou aquelas que se dispunham a escrever eram recebidas ora com críticas acerbas ora com condescendência. Até o século XIX o mundo literário reconhecido era habitado quase que exclusivamente por homens, logo, os padrões estéticos literários partiam dessa premissa, de uma literatura eminentemente masculina e que passa a equivaler como literatura universal.

Assim, não bastaria garantir um espaço de atuação para as escritoras, mas assegurar que esse espaço fosse legítimo, e não marginalizado, como grande parte da história literária tem demonstrado, ao restringir as citações de mulheres escritoras ao mínimo, ou então, colocando-as em capítulos à parte. A crítica feminista tem se dedicado nos últimos tempos a questionar sobre a construção social do gênero, o que significa historicamente ser mulher, considerando as variáveis de tempo e espaço que contextualizam a abordagem. Variáveis que não se aplicam, no entanto, ao poder canônico literário, distante da esfera feminina. Isso, tomando-se por parâmetro as nações democráticas, uma vez que há países com uma 
tradição ainda mais cerceadora em relação ao papel das mulheres. Escrever em séculos anteriores era, portanto, também uma forma de expressar a insatisfação com a diferença de tratamento entre homens e mulheres, além de demonstrar na prática da escrita o princípio iníquo no qual se baseava a sociedade em relação às mulheres no geral e às escritoras em particular.

O feminismo contribuiu para a reavaliação de antigos conceitos, estabeleceu novos posicionamentos em relação aos estereótipos relativos aos temas e gêneros literários, assim como lançou luz às sombras das convenções da escrita produzida por mulheres, que estão passando a sujeitos da história e da criação literária. Ao atacar a ordem constituída em uma sociedade patriarcal, moralista e sexista, contribuiu para o desenvolvimento da literatura de autoria feminina. Atualmente as mulheres têm, na maior parte das vezes, livre acesso à literatura, cabe, no entanto, ponderar-se sobre o poder político desse acesso e os espaços ocupados por essa produção literária.

A partir do momento em que as mulheres tiveram acesso ao saber e o feminismo tomou corpo e forma, o espaço da leitura e da escrita deixou de ser território sagrado. No entanto, mesmo hoje se percebe uma participação desproporcional de escritores e escritoras que contribuem para escrever a história literária contemporânea. A desigualdade simbólica, social e política reflete-se nessa participação literária, o que, de certa forma, mostra que a crítica literária feminista ainda tem muito a fazer.

O feminismo, ao apontar para novas maneiras de se conceber um texto, modificou consequentemente o modo de se ler e valorizar determinada obra, apontando para princípios críticos diversos dos tomados comumente por parâmetros e o cânone literário passa a ser questionado. Compreender a literatura de autoria feminina é, portanto, não se limitar à estreita visão da tradição literária, mas contextualizá-la observando as relações que mantém com outros textos e as estruturas sociais e culturais que compõem o panorama da época. Somente não observando as regras canônicas foi possível conhecer melhor os textos escritos por mulheres, tidos, em geral, como deficientes e secundários. Essa outra maneira de se ler os textos constitui uma história literária escrita sobre diferentes bases, 
cuja intenção é reconhecer a denúncia e subversão de alguns textos escritos por mulheres, com atenção inclusive para os relatos de cunho autobiográfico.

Assim, o ponto principal deste texto é compreender a literatura de autoria feminina como a quase representação do sublime. Tal perspectiva está centrada nessa experiência que resiste a uma categorização, que apresenta um trabalho narrativo diferenciado, instaurando uma fissura na história literária até então constituída. Uma literatura que buscou libertação formal e temática, espécie de desafio ao cânone, elevando-se em relação aos paradigmas.

Em The Feminine Sublime, Barbara Claire Freeman destaca o papel desempenhado pelo gênero no âmbito da crítica literária (Freeman 1995). O conceito sublime vem se desdobrando ao longo do tempo, mas a autora sublinha que o "excesso" sublime, o que extrapola os padrões e modelos, acaba por se neutralizar após o impacto causado. Assim, é possível considerar a literatura de autoria feminina a partir de uma crítica tradicional, mas tal literatura, com seu potencial de renovação e características próprias, se afirma como nova possibilidade no contexto literário, provocando um repensar das bases em que a literatura se constitui. O sublime está associado a essa possibilidade de liberdade e independência. Lyotard destaca que o sublime não é a representação do não-representável, mas o fato de que o não-representável existe, ou seja, garantir o espaço legitimado da diferença. 0 sublime se situa como resistência ao instituído, provocando o repensar da literatura em diferentes dimensões, dentre outras, geográficas, políticas, étnicas, raciais e de gênero. 0 sublime como recusa à uniformização autoritária, e, conforme aponta a autora, torna-se necessário compreender o compromisso sublime como forma de manter uma condição de incerteza radical com a própria condição de sua possibilidade.

Em “Female Sublime”, Paula Rosine Long reflete sobre o papel da crítica a partir dos anos 1970 e pensa o sublime como conceito dinâmico, capaz de ser compreendido com um olhar contemporâneo, considerando as muitas contribuições no decorrer do tempo, porém com sua característica de momento, quando o belo instituído não é capaz de apreender o que se apresenta, conforme a abordagem proposta neste texto intentou demonstrar. 0 sentimento sublime a partir da autoria feminina se aproxima da ruptura, do novo que 
obriga a uma igualmente nova forma de considerar a literatura, impulsionando a discussão de que as diferenças coexistem, legitimamente constituídas.

O posicionamento crítico do sublime feminista destaca o descompasso da afirmação de que a arte se eleva acima de questões de gênero, raciais e de outras identidades socialmente marcadas, pois na prática essas ausências ou sub-representações se fazem sentir no contexto paradigmático. Ainda que isso possa ser estatisticamente verificável, mantém-se essa postura de neutralidade nas artes e cabe, portanto, provocar o debate no sentido de se avançar em relação à questão. A crítica feminista se contrapõe à postura tradicionalista da estética, que considera um sujeito universal e juízos de gosto universalistas, mas que pressupõem o apagamento das diferenças. 0 sublime torna-se um conceito relevante para o feminismo justamente porque aí reside a fratura, ao assumir a possibilidade do excesso, da diferença que assusta e atrai concomitantemente. Nesse sentido, conforme já salientado, cabe admitir o desafio dessa diversidade, em uma postura ética de respeito e aceitação dessas diferenças.

A experiência sublime coloca o sujeito diante de uma magnitude quase impossível de ser apreendida, conforme destaca Deleuze em sua reflexão sobre o sublime. Essa grandeza pode estar associada à natureza, fenômenos sublimes como as tormentas, mas há também a possibilidade de magnitudes infinitas, aquelas que desafiam a capacidade humana de compreensão, a qual está limitada ao finito. 0 absoluto engendrado pelo infinito desafia essa capacidade humana de intelecção, uma vez que a não possibilidade de mensuração está ligada ao sujeito que contempla, pois é ele quem percebe algo como além de sua capacidade de entendimento. 0 fato de determinado objeto ser maior que a possibilidade de compreendê-lo encadeia uma espécie de angústia ou terror, ocasionado pela inadequação e o medo impresso por essa grandiosidade. Porém, esse estado de ânimo agita as faculdades espirituais, faz com que a pessoa pense de maneira diversa e se afaste dos modelos do belo, incapazes de dar conta da nova experiência, e busque nas faculdades da razão uma forma de dominá-la.

No livro A Filosofia Crítica de Kant, Deleuze aborda o sublime e ressalta que, enquanto se mantém o foco no juízo estético do belo, a razão cumpre um papel secundário, 
uma vez que o entendimento e a imaginação são os fatores determinantes (Deleuze 2000). O sentimento sublime é experimentado de forma diferente do sentimento do belo, pois ocorre diante de uma manifestação perante a qual os limites são confrontados. E assim, ante o imenso, no sentido da capacidade possível de apreensão, a imaginação fica sem quaisquer referenciais. A impotência em face do desconhecido permite repensar o estabelecido, uma vez que reconhece a existência de outras possibilidades, ainda que em determinado momento não existam condições estabelecidas para a sua apreensão e compreensão. A razão é a responsável por impelir a imaginação ao seu limite até chegar ao ponto de reconhecer sua incapacidade diante de uma nova ideia. 0 descompasso estabelecido entre imaginação e razão no fundo estabelece um acordo, centrado na dicotomia prazer/desprazer. Através do sentimento sublime, a imaginação se encontra livre de suas balizas, percebendo o infinito e o absoluto, em uma representação negativa, conforme anteriormente abordado.

A contribuição feminista às reflexões sobre o sublime destaca o compromisso estético e ético, no sentido de considerar a produção literária feminina nesse espaço de ruptura com os padrões instituídos pela literatura e pela crítica literária. Assim, o outro não precisa ser necessariamente associado ao perigo por ameaçar o já instituído, mas poderá ser visto justamente como possibilidade de uma nova perspectiva, na adoção de uma postura de aceitação e respeito às diferenças. Nesse sentido, no sublime feminista há a defesa de mudança desse posicionamento tradicionalmente associado ao sublime, de temor ao novo e consequente afastamento dessa experiência, uma vez que considera o prazer/desprazer como um momento próprio no processo de apreensão e compreensão do que extrapola os limites canônicos, social e culturalmente construídos. 


\section{Bibliografia}

Aristóteles / Horácio / Longino (1981), A poética clássica, São Paulo, Cultrix.

Dalcastagné, Regina / Virgínia Maria Vasconcelos Leal (orgs.) (2010), Deslocamentos de gênero na narrativa brasileira contemporânea, São Paulo, Editora Horizonte.

Deguy, Michel / Jean-Luc Nancy (orgs.) (1988), Du Sublime, Paris, Belin.

Deleuze, Gilles (2000), A filosofia crítica de Kant, tradução de Germiniano Franco, Lisboa, Portugal, Edições 70.

Derrida, Jacques (1978), “Párergon”, La Verité en peinture, Paris, Flammarion, 19-168.

Freeman, Barbara Claire (1995), The Feminine Sublime: Gender and Excess in Women's Fiction, Berkeley, University of California Press.

Hollanda, Heloisa Buarque de (1994), Tendências e impasses: o feminismo como crítica da cultura, Rio de Janeiro, Rocco.

Kamita, Rosana Cássia (2005), Resgates e Ressonâncias: Mariana Coelho, Florianópolis, Ed. Mulheres.

Kant, Immanuel (2001), Crítica da razão pura, tradução de Manuela Pinto dos Santos e Alexandre Fradique Morujão, Lisboa, Fundação Calouste Gulbenkian.

-- (2002), Crítica da razão prática, tradução de Valério Rohden, São Paulo, Martins Fontes.

-- (2002), Crítica da faculdade do juízo, tradução de Valério Rohden, Rio de Janeiro, Forense.

-- (1993), Observações sobre o sentimento do belo e do sublime, tradução de Vinícius Figueiredo, Campinas, Papirus.

Long, Paula Rosine (s.d.), "The Female Sublime”.

Lyotard, Jean François (1993), Lições sobre a analítica do sublime, tradução de Constança Marcondes Cesar, Campinas, Papirus. 
Olinto, Heidrun Krieger / Karl Erik Schollhammer (orgs.) (2009), Literatura e Crítica, Rio de Janeiro, 7Letras.

Schiller, Friedrich (2011), Do Sublime ao Trágico, organização de Pedro Süssekind, tradução e ensaios Pedro Süssekind e Vladimir Vieira, Belo Horizonte, Autêntica Editora.

Woolf, Virginia (1985), Um teto todo seu, tradução de Vera Ribeiro, Rio de Janeiro, Nova Fronteira.

Rosana Cássia Kamita é Professora Associada da Universidade Federal de Santa Catarina (Brasil), atuando na Graduação em Letras e Pós-Graduação em Literatura. Coordenadora do Grupo de Trabalho A Mulher na Literatura, da Anpoll (Associação Nacional de PósGraduação em Letras e Linguística), no biênio 2014-2016. Integrante do Grupo de Pesquisa do Instituto de Estudos de Gênero - IEG/UFSC. Integrante da Editoria de Artigos da Revista Estudos Feministas - REF. Coordenadora do Núcleo Literatual - Estudos Feministas e PósColoniais de Narrativas da Contemporaneidade. Co-Coordenadora do IEG - Instituto de Estudos de Gênero, da Universidade Federal de Santa Catarina. Bolsista de Produtividade em Pesquisa do CNPq - Nível 2. 